\title{
Impact of COVID-19 on carers of people with dementia in the community: Findings from the IDEAL cohort
}

\section{Catherine Quinn ( $\nabla$ c.quinn1@bradford.ac.uk)}

Centre for Applied Dementia Studies, University of Bradford https://orcid.org/0000-0001-9553-853X

\section{Laura D. Gamble}

Population Health Sciences Institute, Newcastle University

\section{Sophie Parker}

College of Medicine and Health, University of Exeter

\section{Anthony Martyr}

College of Medicine and Health, University of Exeter

\section{Rachel Collins}

College of Medicine and Health, University of Exeter

\section{Christina Victor}

e. College of Health, Medicine and Life Sciences, Brunel University London

\section{Eleanor Dawson}

College of Medicine and Health, University of Exeter

\section{Anna Hunt}

College of Medicine and Health, University of Exeter

\section{Claire Pentecost}

College of Medicine and Health, University of Exeter

\section{Louise Allan}

College of Medicine and Health, University of Exeter

\section{Linda Clare}

College of Medicine and Health, University of Exeter

\section{Research Article}

Keywords: Coping, life satisfaction, stress, support, well-being

Posted Date: March 1st, 2022

DOI: https://doi.org/10.21203/rs.3.rs-1404546/v1 
License: (c) (i) This work is licensed under a Creative Commons Attribution 4.0 International License. Read Full License

Version of Record: A version of this preprint was published at International Journal of Geriatric Psychiatry on March 24th, 2022. See the published version at https://doi.org/10.1002/gps.5708. 


\section{Abstract \\ Background}

Unpaid carers for people with dementia play a crucial role in society. Emerging evidence suggests the COVID-19 pandemic has negatively impacted on carers.

\section{Objective}

To explore the impact of the COVID-19 pandemic on carers for community-dwelling people with dementia and compare responses with pre-pandemic data.

\section{Methods}

Data were collected between September 2020 and April 2021 in England and Wales. Carers were identified from the IDEAL cohort and data were collected either through the telephone, video conferencing or an online questionnaire. Responses from 242 carers were compared against benchmark data from the IDEAL cohort. Analyses were conducted for the full sample of carers and for the spousal/partner carers only.

\section{Results}

$48.8 \%$ of carers identified their healthcare needs were negatively affected during the pandemic. Compared with pre-pandemic data carers were more optimistic and had higher social contact with relatives. There were changes in the methods carers used for contacting relatives and friends. Carers were more lonely and experienced less life satisfaction. Most carers coped very or fairly well during the pandemic. There was little impact on carers' experience of caregiving, although carers felt trapped by the person's dementia. There was little difference in the experiences of spousal/partner carers and the full sample.

\section{Conclusions}

To some extent carers were coping with the pandemic but clearly would benefit from support in terms of alleviating feelings of loneliness and increasing life satisfaction. Services need to consider how to improve access to health care under conditions such as those experienced during the pandemic.

\section{Key Points}

- Carers have played a vital role in supporting people with dementia during the COVID-19 pandemic. 
- Carers need to be appropriately supported to ensure they are as satisfied as possible with their lives.

- Carers need more opportunities for social contact outside of the caring role.

- Healthcare services need to consider how to improve and maintain access to health care under pandemic conditions.

\section{Background}

Many people are living with a diagnosis of dementia, with estimates from 2014 suggesting that in the United Kingdom (UK) 850,000 people were living with dementia. ${ }^{1}$ Figures from the UK indicate the total costs of dementia amount to $£ 34.7$ billion, with unpaid care accounting for $40 \%$ of these costs. ${ }^{2}$ This highlights the crucial role that carers, often family members, or friends, have within society. Those caring for people with dementia are often giving extensive assistance over a long period of time. ${ }^{3}$ Multiple factors can influence the capability of carers to live well, such as psychological health, physical fitness and health, and their experiences of caregiving. ${ }^{4}$ The carer's well-being can also influence the well-being of the person with dementia. ${ }^{5}$ Although carers can identify positive experiences in providing care, ${ }^{6,7}$ it is clear that caregiving can take a considerable toll on the health and well-being of carers ${ }^{3,8,9}$ and they need appropriate support. ${ }^{10}$

The COVID-19 pandemic has negatively impacted on people with dementia and carers. Between March and June 2020 in England and Wales, 27.5\% of people who died from COVID-19 had dementia and the largest increase in non-COVID-19 deaths was in people with dementia. ${ }^{11}$ Within the UK, periods of national and local lockdowns and periods of restrictions meant that carers had fewer opportunities for respite and experienced reduced access to health and social care. ${ }^{11-13}$ There is emerging evidence of the impact of the pandemic on carers. Qualitative studies have highlighted that for carers, the pandemic exacerbated an already difficult situation having a negative impact on well-being ${ }^{12,14-17}$. Given the unprecedented situation and the speed in which data were collected, some quantitative studies just focused on reporting data collected during the pandemic; for example, rates of anxiety, depression, and stress in carers during periods of lockdown/confinement. ${ }^{18-20}$ Although these data provide a helpful description of carers' well-being, without details of the pre-COVID context, these studies cannot explore the wider impact of the pandemic and resulting restrictions on carers. Retrospective accounts, where carers compare their current situation to a time before the pandemic started ${ }^{21-33}$ suggest that some carers described increased care needs of the person with dementia, ${ }^{26,28,30}$ self-reported stress, ${ }^{22,25}$ burden, ${ }^{23,34}$ Ioneliness, ${ }^{24}$ anxiety and depression, ${ }^{24,27,33}$ although a worsening of well-being was not universal for all carers taking part in these studies.

Whilst retrospective accounts rely on carers accurately recalling the situation pre-pandemic, other studies have compared data collected at different timepoints during the pandemic. Some studies comparing data collected prior to and during periods of lockdown/confinement report increases in carer stress, ${ }^{35}$ burden, ${ }^{36,37}$ and worsening of well-being ${ }^{37}$ during lockdown. However, other studies reported no changes 
in carer health-related quality of life ${ }^{38}$ or distress. ${ }^{39} \mathrm{~A}$ study that collected data over three timepoints found that although anxiety, depression, and stress increased when assessed at the end of a lockdown period, these levels had started to decrease two months later. ${ }^{40}$ These findings suggest that things may change over time as carers adjust to the situation. Whilst these studies start to provide an important picture of changes in carers' circumstances, due to the nature of data collection, these studies typically relied on audits of health records and samples of convenience.

Currently there is no study of carers of people with dementia that has compared the current impact of the pandemic with equivalent pre-pandemic information; this would provide important insights into changes experienced by carers during the pandemic. The aim of this study was to explore the impact of the pandemic on carers of people with dementia who were already participating in the Improving the experience of Dementia and Enhancing Active Life (IDEAL) cohort, ${ }^{41,42}$ thus allowing comparison of data collected during the second wave of the pandemic with pre-pandemic data.

\section{Method}

\section{Design}

This study was cross-sectional where data collected from carers of people with dementia during the COVID-19 pandemic were compared against benchmarked data collected before the pandemic as part of IDEAL. INCLUDE (Identifying and mitigating the individual and dyadic impact of COVID-19 and life under physical distancing on people with dementia and carers) focussed specifically on the impact of the pandemic on people with dementia and carers. ${ }^{43}$ Data were collected between September $21^{\text {st }} 2020$ and April $30^{\text {th }} 2021$ in participants living in England and Wales. This was a period of continuing and changing restrictions, with local and national lockdowns, and the commencement of the vaccination programme in December 2020.

IDEAL recruited people with dementia and carers. At Time 1 (T1) there were 1,537 community-dwelling people with mild-to-moderate dementia and 1,277 carers recruited from 29 National Health Service sites within England, Scotland, and Wales between June 2014 and August 2016. The cohort was followed up yearly for two further timepoints. A further study, IDEAL-2, would have followed the cohort for three additional timepoints (T4- T6). Data collection for T4, however, was affected by the pandemic. As part of IDEAL-2, an enrichment cohort was recruited to increase the number of people with rarer dementias, young onset dementia, and people over 90. Participants recruited into INCLUDE comprised of people from IDEAL and enrichment cohorts. ${ }^{43}$

Here we compared data collected from carers taking part in the INCLUDE study against data taken from IDEAL T3, the most recent complete dataset, collected from 706 carers of people with dementia residing in the community between 2016-2018. This study focuses on carers of community-dwelling people with dementia, thus carers of people living in care were excluded from analyses. 
IDEAL was approved by Wales Research Ethics Committee 5 (reference 13/WA/0405) and IDEAL-2 by Wales Research Ethics Committee 5 (reference 18/WS/0111) and Scotland A Research Ethics Committee (reference 18/SS/0037). INCLUDE was approved as an amendment to IDEAL-2 for England and Wales (18/WS/0111 AM12). IDEAL and IDEAL-2 are registered with the UK Clinical Research Network (UKCRN), numbers 16593 and 37955.

\section{Participants}

Participants were eligible to take part in INCLUDE if they were living in England or Wales and had previously participated in IDEAL. Carers could participate if the person with dementia was not taking part.

\section{Measures}

The structured interview drew on the domains of living well explored previously ${ }^{42}$, incorporating single items used in IDEAL and additional questions focusing on experiences during the pandemic. The questions covered health, social networks, psychological well-being, and caregiving experiences. A full description of the measures is provided in Supplementary Tables 2-5.

\section{Procedure}

Data was collected by three trained interviewers who were graduate or masters level psychologists. Potential participants were contacted either through letter, telephone, or email. During this initial contact, interviewers provided information about the study and answered questions. A follow-up call was arranged to take informed consent. Carers could either be interviewed over the telephone, video conferencing, or self-complete the questionnaire online.

\section{Data analyses}

Questions on experiences during the pandemic were analysed descriptively. The other items were compared against IDEAL T3 data. Version 5 of the IDEAL datasets was used. Depending on whether the data were categorical or ordinal, chi-square or Mann-Whitney $U$ tests were used to compare the difference in responses prior to and during the COVID-19 pandemic. As INCLUDE participants comprised people from both the main IDEAL cohort and the enrichment cohort, in relation to the T3 data INCLUDE responses contained a mixture of paired and independent responses. Therefore, sensitivity analyses were conducted using the 'PartitallyOverlapping' package in $\mathrm{R}$ which compares proportions using the partially overlapping samples z-test (for categorical variables) and means through the partially overlapping t-test (for continuous and ordinal variables). Differences in the paired samples were additionally explored using the Friedman and McNemar's chi-squared tests.

Analyses were conducted for the full sample of carers. Since most of the carers were spouses/partners, we explored this specific group to determine if there were any differences in responses. 


\section{Results}

Out of the 584 eligible carers, researchers contacted 496. Of these 288 agreed to participate; 46 carers were excluded from the current study as the person with dementia was in residential care yielding a sample of 242 carers. Participants are described in Table 1; most carers were female (68.2\%) and spouse/partners (85\%).

\section{Health and health care}

Reponses are provided in Table 2 and Supplementary Table 2. For the full sample (both spouse/partners and family/friends) a small percentage had contracted COVID-19, which was lower than population norms ( $4.1 \%$ vs $6.1 \%)$. In total $21.1 \%$ reported knowing someone close to them who had contracted COVID-19. The pandemic impacted on carers' health with $48.8 \%$ reporting their healthcare needs were affected. This related to cancelled or postponed hospital appointments, operations, and medical reviews. There were difficulties getting appointments with General Practitioners, opticians, and dentists, particularly face-to-face appointments. Only $24 \%$ avoided seeking help for health issues, primarily due to not wanting to burden services, feeling the issue was not urgent, fear of contracting COVID-19 in medical settings, and dislike of telephone appointments. Analyses on spouse/partner carers only yielded similar findings.

\section{Social network}

Responses are provided in Table 3 and Supplementary Table 3. For the full sample, there was a significant increase in the number of relatives the carer was in contact with at least monthly compared to IDEAL T3 (6.2 vs 5.3) which was also supported by the sensitivity analyses (Supplementary Table 6). When asked, $45.9 \%$ of carers said this contact had changed since the pandemic. Responses indicate changes related to less face-to-face contact and an increased use of telephone/virtual contact.

Although not significant, carers reported more satisfaction with support from relatives ( $77.2 \%$ vs $68.8 \%$ ). The number of friends in contact at least monthly was not significantly different, though $56.2 \%$ of carers said this had changed since the pandemic for similar reasons as above. The increase in satisfaction with support from friends $(73.6 \%$ vs $62.6 \%)$ was not significant. Similar findings were observed for spouse/partner carers only.

\section{Psychological well-being and quality of life}

For the full sample, significantly more carers reported feeling lonely than at IDEAL T3 ( $54.5 \%$ vs $28.7 \%$ ); they also reported slightly less life satisfaction (6.1 vs 6.6), see Table 4 and Supplementary Table 4. These findings were supported by the sensitivity analyses (Supplementary Table 6). Carers were more optimistic, expecting more good things to happen than bad (56.7\% vs $53.4 \%)$, and this was supported by the paired samples tests (Supplementary Table 6). Other measures of well-being were not significantly different. Findings for spouse/partners only were similar although fewer spouses/partners reported having a good or very good quality of life ( $54.3 \%$ vs $58.2 \%$ ), a difference which was lost when combining 
them with family/friend carers. However, this was not supported in the sensitivity analysis (Supplementary Table 7).

Most carers felt that they had coped very or fairly well during the pandemic (94.7\%) and around half identified that the pandemic had positive aspects (55.8\%). Most carers found it easy to keep themselves occupied (85.1\%). Findings were similar for spouse/partner carers only.

\section{Carers' experience of caregiving}

Compared with IDEAL T3 more carers felt trapped by the person's dementia (42.2\% vs $37.1 \%$ ). However, this finding was not supported in the sensitivity analyses (Supplementary Table 6). In terms of support available, carers were more likely to identify someone to step in to help generally (50\% vs $35.4 \%$ ) and if the carer needed a break ( $40.9 \%$ vs $28.2 \%)$. These findings were supported by the sensitivity analyses. Findings were similar when looking at spouse/partner carers only, see Table 5 and Supplementary Table 5 .

Other care-related questions did not show any significant differences, with similar findings in all carers and spouses/partners only. There was no difference in the quality of the dyadic relationship. More carers reported improvements in their ability to cope with caregiving (70.3\% vs $63.8 \%)$, ability to meet the person's needs ( $82.2 \%$ vs $80.3 \%)$, and competency in their ability to care $(83.5 \%$ vs $80.5 \%)$. There was little difference in the proportion saying that they got along with the person with dementia $(83.9 \% \mathrm{vs}$ $82.2 \%)$. Slightly fewer reported feeling they were doing a good job as a carer $(75.2 \%$ vs $77 \%)$. More reported wishing to be free to lead a life of their own ( $36.4 \%$ vs $33 \%)$ and that they could run away ( $23.9 \%$ vs $17.6 \%)$.

\section{Discussion}

To the best of our knowledge this is the first study to compare the impact of the COVID-19 pandemic on carers of people with dementia with equivalent pre-pandemic data. The current study involved carers from the IDEAL cohort, providing a unique insight into the effect of the pandemic on carers. Overall, findings were equivocal indicating some impact on carers' health, social contact, well-being, and experience of caregiving. There was little difference when considering the experiences of spouses/partners only versus the full sample.

Although there was no difference in carers' overall health, just under half said their healthcare needs were affected by the pandemic with difficulties accessing medical appointments and treatments. This may reflect wider issues relating to access to healthcare for people with dementia and carers ${ }^{11}$ and the move to more remote consultations. Approximately half of carers identified changes in contact with relatives and friends, and there was increased contact with relatives compared with IDEAL T3. The findings indicate carers have used telephone/technology to connect with others during the pandemic, similar to other findings. ${ }^{17,22}$ Despite this increased contact, carers were significantly lonelier when compared to IDEAL T3, which aligns with findings from other studies. ${ }^{12,24}$ This finding may reflect a lack of 
relationship closeness, particularly if the main source of contact is the person with dementia. There may have been fewer opportunities to have meaningful face-to-face contact with others outside the household.

Other well-being findings were equivocal. Carers had lower life satisfaction than at T3. Other studies have not yet explored life satisfaction in carers during the pandemic. The pandemic would have brought about many changes to the lives of carers and this potentially could have impacted on their overall life satisfaction. There is also evidence of a link between low life satisfaction and loneliness. ${ }^{44}$ Interestingly, carers were more optimistic, and similar findings have been reported in people with dementia. ${ }^{43}$ Increased optimism may be a form of coping, concordant with theories that positive and negative psychological states can co-occur during stressful circumstances ${ }^{45}$ and finding meaning in adversity can be a form of coping. ${ }^{6,46}$ Certainly, just over half of the carers identified that the pandemic had some positives and most carers reported coping well during the pandemic. Although studies have reported carers struggling to cope during the pandemic ${ }^{13}$ others have reported carers coping well 27 utilising active and passive coping strategies. ${ }^{19}$ Our findings may reflect carers' adaptation to the situation.

There was very little impact on the carers' experience of caregiving. Compared with IDEAL T3 more carers felt trapped by the person's dementia. It is possible that with people with dementia being identified as more clinically vulnerable to COVID-19 47 this placed additional pressure on carers to keep them safe. More carers were able to identify someone that could provide help than at IDEAL T3. This finding may seem contradictory with carers reporting increased caregiving responsibilities ${ }^{12,28,37}$ and a lack of access to formal support services ${ }^{13}$. However, it may reflect that most carers had increased contact with family and thus a larger support network. Equally it may reflect the data collection period which started nine months into the pandemic by which time some support services had restarted, albeit often through remote delivery.

It is important to recognise limitations of the study. Data collection was through the use of single items from validated measures, limiting the range of data collected. However, this approach was to reduce burden on carers and allow comparison with existing IDEAL data. For the analyses, data from INCLUDE participants were compared with IDEAL T3 data, collected between 2016 and 2018, the last complete timepoint. Thus, it is important to acknowledge this gap when comparing findings with benchmarked data. The differences observed may not necessarily be solely attributable to the pandemic; however, they do provide an indication of what might have changed.

Both the existing IDEAL and enrichment cohorts were used to identify participants for the current study, and while the participants were similar the enrichment cohort included a higher proportion of younger carers (<65). The carers who participated in INCLUDE may have been coping better than those who declined to take part. However, unpublished qualitative interviews with INCLUDE carers illustrate the challenges they faced and align with our reflection that they have had little choice but to 
cope. The statistical tests employed assumed the INCLUDE and IDEAL T3 samples were independent of each other, but they were partially overlapping and incorporated both paired and unpaired samples. Therefore, sensitivity analyses were conducted using the partially overlapping t-test or z-test, and paired samples tests on paired data only. The partially overlapping tests were not able to handle categorical variables but since the categorical variables were ordered they were treated as ordinal and t-tests were conducted. ${ }^{48}$ Therefore, findings need to be interpreted with caution when the sensitivity analyses do not concur with the results of the main analyses.

The study provides some important insights into the experiences of carers during the pandemic, exploring domains not previously reported in other studies. Given carers reported their healthcare needs had been affected it is important to consider how access to healthcare and healthcare delivery can be improved. Further research is needed to explore the long-term impact of the pandemic on access to health care, particularly with the increased use of telemedicine. ${ }^{49}$ Loneliness in carers was already an issue prepandemic ${ }^{44}$; therefore, better support is needed to increase opportunities for social contact and to enable individuals to develop good quality relationships with others. Equally, carers had lower life satisfaction indicating the need for greater investment in supporting carers in their role. ${ }^{50}$ Although the findings indicate that generally carers coped well, it may be that carers had little choice but to adjust to and cope with the situation. The long-term effects of this are unknown. Carers have played a vital role within this pandemic and they need to be appropriately supported to enable them to continue within their caregiving role.

\section{References}

1. Alzheimer's Society. Dementia UK. London2014.

2. Wittenberg R, Hu B, Barraza-Araiza L, Rehill A. Projections of older people with dementia and costs of dementia care in the United Kingdom, 2019-2040. London: Care Policy and Evaluation Centre, London School of Economics and Political Science;2019.

3. Alzheimer's Association. 2018 Alzheimer's disease facts and figures Alzheimer's \& Dementia. 2018;14:367-429.

4. Clare L, Wu YT, Quinn C, et al. A comprehensive model of factors associated with capability to "Live Well" for family caregivers of people living with mild-to-moderate dementia: Findings from the IDEAL Study. Alzheimer Dis Assoc Disord. 2019;33(1):29-35. 10.1097/WAD.0000000000000285

5. Quinn C, Nelis SM, Martyr A, Morris RG, Victor C, Clare L. Caregiver influences on 'living well' for people with dementia: Findings from the IDEAL study. Aging Ment Health. 2020;24(9):1505-1513. $10.1080 / 13607863.2019 .1602590$

6. Quinn C, Toms G. Influence of positive aspects of dementia caregiving on caregivers' well-being: A systematic review. Gerontologist. 2019;59(5):e584-e596. 10.1093/geront/gny168 
7. Quinn C, Nelis SM, Martyr A, et al. Influence of positive and negative dimensions of dementia caregiving on caregiver well-being and satisfaction with life: findings from the IDEAL study. Am J Geriatr Psychiatry. 2019;27(8):838-848. 10.1016/j.jagp.2019.02.005

8. Collins RN, Kishita N. Prevalence of depression and burden among informal care-givers of people with dementia: a meta-analysis. Ageing Soc. 2020;40:2355-2392.

9. $\quad$ CarersUK. State of Caring 2019. London2019.

10. Future Health \& Alzheimer's Society. Stabilise, energise, realise: a long term plan for social care. 2021.

11. Alzheimer's Society. Worst hit: dementia during coronavirus. 2020.

12. Hanna K, Giebel C, Tetlow H, et al. Emotional and mental wellbeing following COVID-19 public health measures on people living with dementia and carers. J Geriatr Psychiatry Neurol. 2021. $10.1177 / 0891988721996816$

13. Roach P, Zwiers A, Cox E, et al. Understanding the impact of the COVID-19 pandemic on wellbeing and virtual care for people living with dementia and care partners living in the community. Dementia. 2021;20(6):2007-2023. 10.1177/1471301220977639

14. Keng A, Brown EE, Rostas A, et al. Effectively caring for individuals with behavioral and psychological symptoms of dementia during the COVID-19 pandemic. Front Psychiatry. 2020;11:573367. 10.3389/fpsyt.2020.573367

15. Rajagopalan J, Arshad F, Hoskeri RM, et al. Experiences of people with dementia and their caregivers during the COVID-19 pandemic in India: A mixed-methods study. Dementia 2021. $10.1177 / 14713012211035371$

16. O'Rourke G, Pentecost C, van den Heuvel E, et al. Living with dementia under COVID-19 restrictions: coping and support needs among people with dementia and carers from the IDEAL cohort. Ageing Soc. 2021:1-23. 10.1017/s0144686x21001719

17. Sriram V, Jenkinson C, Peters M. Impact of COVID-19 restrictions on carers of persons with dementia in the UK: a qualitative study. Age Ageing. 2021;50(6):1876-1885. 10.1093/ageing/afab156

18. Rainero I, Bruni AC, Marra C, et al. The impact of COVID-19 quarantine on patients with dementia and family caregivers: A nation-wide survey Front Aging Neurosci. 2020;12:625781.

10.3389/fnagi.2020.625781

19. Savla J, Roberto KA, Blieszner R, McCann BR, Hoyt E, Knight AL. Dementia caregiving during the "stay-at-home" phase of COVID-19 pandemic. J Gerontol B Psychol Sci Soc Sci. 2021;76(4):e241-e245. 10.1093/geronb/gbaa129 
20. Borelli WV, Augustin MC, de Oliveira PBF, et al. Neuropsychiatric symptoms in patients with dementia associated with increased psychological distress in caregivers during the COVID-19 Pandemic. J Alzheimers Dis. 2021;80(4):1705-1712. 10.3233/JAD-201513

21. Pongan E, Dorey J-M, Borg C, et al. COVID-19: Association between increase of behavioral and psychological symptoms of dementia during lockdown and caregivers' poor mental health. $J$ Alzheimers Dis. 2021;80(Preprint):1713-1721,.

22. Tam MT, Dosso JA, Robillard JM. The impact of a global pandemic on people living with dementia and their care partners: Analysis of 417 lived experience reports. $J$ Alzheimers Dis. 2021;80(2):865-875. 10.3233/JAD-201114

23. Tsapanou A, Papatriantafyllou JD, Yiannopoulou K, et al. The impact of COVID-19 pandemic on people with mild cognitive impairment/dementia and on their caregivers. Int $J$ Geriatr Psychiatry. 2021;36(4):583-587. 10.1002/gps.5457

24. van Maurik IS, Bakker ED, van den Buuse S, et al. Psychosocial effects of Corona measures on patients with dementia, mild cognitive impairment and subjective cognitive decline. Front Psychiatry. 2020;11:585686. 10.3389/fpsyt.2020.585686

25. Zucca M, Isella V, Di Lorenzo R, et al. Being the family caregiver of a patient with dementia during the coronavirus disease 2019 lockdown. Front Aging Neurosci. 2021;13:653533. 10.3389/fnagi.2021.653533

26. Rusowicz J, Pezdek K, Szczepanska-Gieracha J. Needs of Alzheimer's charges' caregivers in Poland in the Covid-19 pandemic-An observational study. Int J Environ Res Public Health. 2021;18(9). 10.3390/ijerph18094493

27. Losada A, Vara-Garcia C, Romero-Moreno R, et al. Caring for relatives with dementia in times of COVID-19: Impact on caregivers and care-recipients. Clin Gerontol. 2021:1-15.

$10.1080 / 07317115.2021 .1928356$

28. Kostyal LA, Szeman Z, Almasi VE, et al. Impact of the COVID-19 pandemic on family carers of older people living with dementia in Italy and Hungary. Sustainability. 2021;13(13). 10.3390/su13137107

29. Altieri M, Santangelo G. The psychological impact of COVID-19 pandemic and lockdown on caregivers of people with dementia. Am J Geriatr Psychiatry. 2021;29(1):27-34.

10.1016/j.jagp.2020.10.009

30. Borg C, Rouch I, Pongan E, et al. Mental health of people with dementia during COVID-19 pandemic: What have we learned from the first wave? J Alzheimers Dis. 2021;82(4):1531-1541. 10.3233/jad-210079 
31. Boutoleau-Bretonniere C, Pouclet-Courtemanche H, Gillet A, et al. Impact of Confinement on the Burden of Caregivers of Patients with the Behavioral Variant of Frontotemporal Dementia and Alzheimer Disease during the COVID-19 Crisis in France. Dement Geriatr Cogn Dis Extra. 2020;10(3):127-134. $10.1159 / 000511416$

32. Cohen G, Russo MJ, Campos JA, Allegri RF. Living with dementia: increased level of caregiver stress in times of COVID-19. Int Psychogeriatr. 2020;32(11):1377-1381. 10.1017/S1041610220001593

33. Carcavilla N, Pozo AS, Gonzalez B, et al. Needs of dementia family caregivers in Spain during the COVID-19 pandemic J Alzheimers Dis. 2021;80(2):533-537. 10.3233/JAD-201430

34. Cohen G, Russo MJ, Campos JA, Allegri RF. COVID-19 Epidemic in Argentina: Worsening of behavioral symptoms in elderly subjects with dementia living in the community. Front Psychiatry. 2020;11:866. 10.3389/fpsyt.2020.00866

35. Koh ZY, Law F, Chew J, Ali N, Lim WS. Impact of Coronavirus disease on persons with dementia and their caregivers: An audit study. Ann Geriatr Med Res. 2020;24(4):316-320. 10.4235/agmr.20.0059

36. Panerai S, Prestianni G, Musso S, et al. The impact of COVID-19 confinement on the neurobehavioral manifestations of people with Major Neurocognitive Disorder and on the level of burden of their caregivers. Life Span Disabil. 2020;23(2):303-320.

37. Borges-Machado F, Barros D, Ribeiro O, Carvalho J. The Effects of COVID-19 Home Confinement in Dementia Care: Physical and Cognitive Decline, Severe Neuropsychiatric Symptoms and Increased Caregiving Burden. Am J Alzheimers Dis Other Demen. 2020;35:1533317520976720.

$10.1177 / 1533317520976720$

38. Lara B, Carnes A, Dakterzada F, Benitez I, Piñol-Ripoll G. Neuropsychiatric symptoms and quality of life in Spanish patients with Alzheimer's disease during the COVID-19 lockdown. Eur J Neurol. 2020;27(9):1744-1747. 10.1111/ene.14339

39. Carbone E, Palumbo R, Di Domenico A, Vettor S, Pavan G, Borella E. Caring for people with dementia under COVID-19 restrictions: A pilot study on family caregivers. Front Aging Neurosci. 2021;13:652833. 10.3389/fnagi.2021.652833

40. Moretti R, Caruso P, Giuffre M, Tiribelli C. COVID-19 Lockdown effect on not institutionalized patients with dementia and caregivers. Healthcare. 2021;9(7). 10.3390/healthcare9070893

41. Silarova B, Nelis SM, Ashworth RM, et al. Protocol for the IDEAL-2 longitudinal study: following the experiences of people with dementia and their primary carers to understand what contributes to living well with dementia and enhances active life. BMC Public Health. 2018;18(1):1214.

https://doi.org/10.1186/s12889-018-6129-7 
42. Clare L, Nelis SM, Quinn C, et al. Improving the experience of dementia and enhancing active life-living well with dementia: study protocol for the IDEAL study. Health Qual Life Outcomes. 2014;12(1):164. https://doi.org/10.1186/s12955-014-0164-6

43. Clare L, Martyr, A., Gamble, L.D., Pentecost, C., Collins, R., Dawson, E., Hunt, A., Parker, S., Allan, L., Burns, A., Hillman, A., Litherland, R., Quinn, C., Mathews, F.E., \& Victor, C. . Impact of COVID-19 on 'living well' with mild-to-moderate dementia in the community: findings from the IDEAL cohort. $J$ Alzheimers Dis. 2021. 10.3233/JAD-215095

44. Victor CR, Rippon I, Quinn C, et al. The prevalence and predictors of loneliness in caregivers of people with dementia: findings from the IDEAL programme. Aging Ment Health. 2021;25(7):1232-1238. $10.1080 / 13607863.2020 .1753014$

45. Folkman S. Positive psychological states and coping with severe stress. Soc Sci Med. 1997;45(8):1207-1221. 10.1016/s0277-9536(97)00040-3

46. Quinn C, Clare L, Woods RT. The impact of motivations and meanings on the wellbeing of caregivers of people with dementia: A systematic review. Int Psychogeriatr. 2010;22(1):43-55. $10.1017 /$ S1041610209990810

47. Alzheimer's Society. Dementia and risk from coronavirus. 2021; https://www.alzheimers.org.uk/get-support/coronavirus/dementia-risk. Accessed 01/11/2021, 2021.

48. Derrick B, P W. Methods for comparing the responses from a Likert question, with paired observations and independent observations in each of two samples. Int $\mathrm{J}$ of Mathematics and Statistics. 2018;19:84-93.

49. Stokel-Walker C. Why telemedicine is here to stay. BMJ. 2020;371:m3603. 10.1136/bmj.m3603

50. Alzheimer's Society. The Fog of Support: An inquiry into the provision of respite care and carers assessments for people affected by dementia. London: Alzheimer's Society;2020.

\section{Tables}

Table 1. Characteristics of the carers of people with dementia 


\begin{tabular}{|c|c|c|c|}
\hline & & $\begin{array}{l}\text { Entire } \\
\text { cohort }\end{array}$ & $\begin{array}{l}\text { Spouses/partners } \\
\text { only }\end{array}$ \\
\hline & & $\mathrm{N}(\%)$ & $\mathrm{N}(\%)$ \\
\hline Carer Sex & Female & $165(68.2)$ & $138(66.3)$ \\
\hline Carer Age & $<65$ & $58(24.0)$ & $37(17.8)$ \\
\hline & $65-69$ & 45 (18.6) & $36(17.3)$ \\
\hline & $70-74$ & $57(23.6)$ & $55(26.4)$ \\
\hline & $75-79$ & $31(12.8)$ & $31(14.9)$ \\
\hline & $80+$ & $51(21.1)$ & $49(23.6)$ \\
\hline Carer ethnicity & White British & $226(93.4)$ & $194(93.3)$ \\
\hline & White Other & $7(2.9)$ & $7(3.4)$ \\
\hline & Other & $3(1.2)$ & $3(1.4)$ \\
\hline & Missing & $6(2.5)$ & $4(1.9)$ \\
\hline Carer education & No qualifications & $33(13.6)$ & $31(14.9)$ \\
\hline & $\begin{array}{l}\text { school leaving certificate at } \\
\text { age } 16\end{array}$ & $55(22.7)$ & $50(24.0)$ \\
\hline & $\begin{array}{l}\text { school leaving certificate at } \\
\text { age } 18\end{array}$ & $66(27.3)$ & $54(26.0)$ \\
\hline & University & $75(30.6)$ & $63(30.3)$ \\
\hline & Missing & $14(5.8)$ & $10(4.8)$ \\
\hline Carer marital status & Single & $6(2.5)$ & \\
\hline & Married; first & $156(64.5)$ & $143(68.8)$ \\
\hline & Remarried & $50(20.7)$ & $49(23.6)$ \\
\hline & Civil partnership & $2(0.8)$ & $2(1.0)$ \\
\hline & Legally separated & $2(0.8)$ & \\
\hline & Divorced & $12(5.0)$ & $5(2.4)$ \\
\hline & Widowed & $1(0.4)$ & \\
\hline & Cohabiting & $12(5.0)$ & $9(4.3)$ \\
\hline & Missing & $1(0.4)$ & \\
\hline Carer relationship & Spouse/partner & 208 (85.9) & $208(100.0)$ \\
\hline & Other family/friend & $34(14.1)$ & $0(0)$ \\
\hline & Page $15 / 20$ & & \\
\hline
\end{tabular}




\begin{tabular}{llll}
\hline Person with dementia sex & Female & $94(38.8)$ & $60(31.6)$ \\
\hline Person with dementia age & $<65$ & $29(12.0)$ & $25(12.0)$ \\
\hline & $65-69$ & $36(14.9)$ & $36(17.3)$ \\
\hline & $70-74$ & $38(15.7)$ & $33(15.9)$ \\
\hline $\begin{array}{l}\text { Person with dementia } \\
\text { diagnosis }\end{array}$ & Alzheimer's disease (AD) & $114(47.1)$ & $103(59.5)$ \\
\hline & Vascular dementia (VaD) & $22(9.1)$ & $17(8.2)$ \\
\hline & Mixed AD and VaD & $35(14.5)$ & $23(11.1)$ \\
\hline & Frontotemporal dementia & $32(13.2)$ & $29(13.9)$ \\
\hline & Parkinson's disease dementia & $11(4.5)$ & $10(4.8)$ \\
\hline & Dementia with Lewy bodies & $20(8.3)$ & $19(9.1)$ \\
\hline & Unspecified/Other & $8(3.3)$ & $7(3.4)$
\end{tabular}

Table 2. Experiences of health and healthcare 


\begin{tabular}{|c|c|c|c|}
\hline & $\begin{array}{l}\text { Benchmark for comparison } \\
\text { where applicable }{ }^{\wedge}\end{array}$ & $\begin{array}{l}\text { All } \\
\text { carers* }\end{array}$ & $\begin{array}{l}\text { Spouse/partners } \\
\text { only* }\end{array}$ \\
\hline & & $\mathrm{n}=242$ & $n=208$ \\
\hline \multicolumn{4}{|l|}{ Direct experience of COVID-19: } \\
\hline Had COVID-19 & Population** & $\begin{array}{l}4.1 \% \\
(6.1 \%)\end{array}$ & $3.8 \%(6.1 \%)$ \\
\hline Treated in hospital for COVID-19 & & $0.4 \%$ & $0.5 \%$ \\
\hline $\begin{array}{l}\text { Someone close to you had } \\
\text { COVID-19 }\end{array}$ & & $21.1 \%$ & $20.2 \%$ \\
\hline \multicolumn{4}{|l|}{ Health during the pandemic: } \\
\hline Overall health poor or very poor & IDEAL T3 & $\begin{array}{l}9.6 \% \\
(8.0 \%)\end{array}$ & $10.6 \%(8.1 \%)$ \\
\hline $\begin{array}{l}\text { Healthcare needs affected by } \\
\text { pandemic }\end{array}$ & & $48.8 \%$ & $48.6 \%$ \\
\hline $\begin{array}{l}\text { Healthcare services stopped due } \\
\text { to pandemic }\end{array}$ & & $21.1 \%$ & $19.2 \%$ \\
\hline
\end{tabular}

*Bold type indicates a statistically significant difference at the $5 \%$ level. ${ }^{\wedge} B e n c h m a r k$ data are shown in brackets after the equivalent data for the current sample. **Population estimate for people aged $50+$ in England as of $8^{\text {th }}$ May 2021; source: https://coronavirus.data.gov.uk/details/download

Table 3. Contact with family and friends 
Benchmark for comparison where applicable $\begin{array}{ll}\text { All carers* } & \begin{array}{l}\text { Spouse/partners } \\ \text { only* }\end{array} \\ n=242 & \end{array}$

$n=208$

\begin{tabular}{|c|c|c|c|}
\hline $\begin{array}{l}\text { Number of relatives in contact at } \\
\text { least monthly }\end{array}$ & IDEAL T3 & $\begin{array}{l}6.2 \pm 3.9 \\
(5.3 \pm 4.4)\end{array}$ & $\begin{array}{l}6.1 \pm 3.9(5.3 \pm \\
4.6)\end{array}$ \\
\hline $\begin{array}{l}\text { Has this changed since the } \\
\text { coronavirus outbreak? Yes }\end{array}$ & & $45.9 \%$ & $45.2 \%$ \\
\hline $\begin{array}{l}\text { Very/slightly satisfied with } \\
\text { support from family }\end{array}$ & IDEAL T3 & $\begin{array}{l}77.2 \% \\
(68.8 \%)\end{array}$ & $78.3 \%(69.9 \%)$ \\
\hline $\begin{array}{l}\text { Number of friends in contact at } \\
\text { least monthly }\end{array}$ & IDEAL T3 & $\begin{array}{l}5.3 \pm 4.9 \\
(5.5 \pm 4.7)\end{array}$ & $\begin{array}{l}5.4 \pm 5.1(5.6 \pm \\
4.7)\end{array}$ \\
\hline $\begin{array}{l}\text { Has this changed since the } \\
\text { coronavirus outbreak? Yes }\end{array}$ & & $56.2 \%$ & $56.7 \%$ \\
\hline $\begin{array}{l}\text { Very/slightly satisfied with } \\
\text { support from friends }\end{array}$ & IDEAL T3 & $\begin{array}{l}73.6 \% \\
(62.6 \%)\end{array}$ & $72.6 \%(61.2 \%)$ \\
\hline
\end{tabular}

*Bold type indicates a statistically significant difference at the 5\% level. ${ }^{\wedge}$ Benchmark data are shown in brackets after the equivalent data for the current sample.

Table 4. Psychological well-being and quality of life 


\begin{tabular}{|c|c|c|c|}
\hline & $\begin{array}{l}\text { Benchmark for } \\
\text { comparison where } \\
\text { applicable }\end{array}$ & $\begin{array}{l}\text { All carers* } \\
n=242\end{array}$ & $\begin{array}{l}\text { Spouse/partners } \\
\text { only* } \\
n=208\end{array}$ \\
\hline Feel lonely (yes, more or less) & IDEAL T3 & $\begin{array}{l}54.5 \% \\
(28.7 \%)\end{array}$ & $52.9 \%(29.9 \%)$ \\
\hline $\begin{array}{l}\text { Cheerful } \& \text { in good spirits }>50 \% \text { of } \\
\text { time last } 2 \text { weeks }\end{array}$ & IDEAL T3 & $\begin{array}{l}66.9 \% \\
(68.0 \%)\end{array}$ & $66.7 \%(68.0 \%)$ \\
\hline $\begin{array}{l}\text { Expect more good things to happen } \\
\text { than bad }\end{array}$ & IDEAL T3 & $\begin{array}{l}56.7 \% \\
(53.4 \%)\end{array}$ & $54.8 \%(53.3 \%)$ \\
\hline Satisfied with life (0 - 10 scale) & IDEAL T3 & $\begin{array}{l}6.1 \pm 2.2 \\
(6.6 \pm 2.1)\end{array}$ & $\begin{array}{l}6.1 \pm 2.2 \\
(6.5 \pm 2.1)\end{array}$ \\
\hline $\begin{array}{l}\text { Feel the things I do are worthwhile (0 } \\
-10)\end{array}$ & IDEAL T3 & $\begin{array}{l}7.2 \pm 2.1 \\
(7.5 \pm 1.9)\end{array}$ & $\begin{array}{l}7.2 \pm 2.2(7.4 \pm \\
1.9)\end{array}$ \\
\hline Good or very good quality of life & IDEAL T3 & $\begin{array}{l}57.8 \% \\
(60.9 \%)\end{array}$ & $54.3 \%(58.2 \%)$ \\
\hline $\begin{array}{l}\text { Coped very or fairly well during the } \\
\text { pandemic }\end{array}$ & & $94.7 \%$ & $95.7 \%$ \\
\hline $\begin{array}{l}\text { Pandemic had positive aspects or } \\
\text { benefits }\end{array}$ & & $55.8 \%$ & $54.8 \%$ \\
\hline $\begin{array}{l}\text { Fairly or very easy to keep oneself } \\
\text { occupied during the pandemic }\end{array}$ & & $85.1 \%$ & $85.1 \%$ \\
\hline
\end{tabular}

Table 5. Carers' experience of caregiving 
Benchmark for comparison where applicable $^{\wedge}$
All Spouse/partners

carers* only*

$\mathrm{n}=\quad \mathrm{n}=208$

242

Competence:

Meeting needs of person with

dementia(most/all of the time)

Doing a good job as a carer (most/all of IDEAL T3 the time)

Feel competent in ability to care (most/all IDEAL T3 of the time)

IDEAL T3

Relationship with person with dementia:
IDEAL T3
$82.2 \%$

$(80.3 \%)$

$\begin{array}{ll}75.2 \% & 75.0 \%(78.3 \%)\end{array}$

$83.5 \%$

$(80.5 \%)$
$82.7 \%(81.2 \%)$

$84.6 \%(81.1 \%)$
IDEAL T3

$70.3 \%$

$(63.8 \%)$
$83.9 \%$

$(82.2 \%)$

\section{Coping:}

Cope as a carer (often/always)

IDEAL T3

If ill, is there
(yes easily)

If needed a break, is there someone to step in to help (yes easily)

IDEAL T3

$50.0 \%$ (35.4\%)

$82.7 \%(81.5 \%)$

Social restrictions:

Role captivity:

Do you wish you were free to lead a life of IDEAL T3 your own (somewhat/very much)

$40.9 \%$

$(28.2 \%)$

$69.8 \%(64.6 \%)$

)
Do you feel trapped by person's dementia IDEAL T3
(somewhat/very much)

Do you wish you could just run away (somewhat/very much)
IDEAL T3 $\begin{array}{ll}36.4 \% & 36.1 \%(31.5 \%) \\ (33.0 \%) & \end{array}$

$\begin{array}{ll}42.2 \% & 43.3 \%(37.4 \%)\end{array}$

$\begin{array}{ll}23.9 \% & 22.6 \%(16.9 \%)\end{array}$

*Bold type indicates a statistically significant difference at the $5 \%$ level. Benchmark data are shown in brackets after the equivalent data for the current sample. 